\section{Estudo \\ cobebate}

em Crestão

Planejamento
Revista Estudo \& Debate, Lajeado, v. 24, n. 2, 2017. ISSN 1983-036X

DOI: http://dx.doi.org/10.22410/issn.1983-036X.v24i2a2017.1292

\title{
COMPORTAMENTO INFORMACIONAL: UM ESTUDO COM ALUNOS DO CURSO DE ADMINISTRAÇÁO
}

\author{
Fernanda Francielle de Oliveira Malaquias ${ }^{1}$, Alisson Luiz Vieira ${ }^{2}$, \\ Daniel Masini Espíndola ${ }^{3}$, Gabriel Carvalho Gomes ${ }^{4}$, Matheus Henrique Rosa ${ }^{5}$, \\ Rafael Dias da Silva ${ }^{6}$
}

\begin{abstract}
Resumo: Estudos sobre o uso e os usuários da informação são importantes para que se compreenda as necessidades informacionais dos indivíduos, para que seja avaliado até que ponto os serviços/recursos oferecidos respondem a essas necessidades e se se estáo sendo utilizados adequadamente. Apesar da relevância deste tema, estudos com estudantes da área de negócios ainda mostram-se escassos. Neste contexto, o objetivo geral desta pesquisa é analisar o comportamento informacional dos alunos do curso de Administraçáo matriculados em uma Universidade Pública do Estado de Minas Gerais. Para isto, foi adotada a abordagem qualitativa e a coleta de dados foi realizada por meio de entrevistas semiestruturadas. Os principais resultados mostram que fontes de informaçóes como livros, a internet, professores e os colegas de turma são componentes importantes do comportamento informacional dos alunos entrevistados. Observou-se que as necessidades informacionais dos estudantes estão relacionadas principalmente com as suas atividades acadêmicas e profissionais. Estes resultados mostram-se relevantes para fundamentar políticas educacionais/pedagógicas em instituiçóes de ensino superior, especialmente quando se considera que a aptidão para assimilar novas informaçóes está entre as características desejáveis dos egressos do curso de Administração.
\end{abstract}

Palavras-chave: Informação. Conhecimento. Necessidades Informacionais.

1 Professora da Universidade Federal de Uberlândia. Possui Graduação e Mestrado em Ciência da Computação, com Doutorado em Engenharia Elétrica pela UFU. Em 2015, desenvolveu sua pesquisa de pós-doutorado na DePaul University (Chicago, EUA).

2 Aluno do curso de Administração de Empresas (FAGEN/UFU).

3 Aluno do curso de Administração de Empresas (FAGEN/UFU).

4 Aluno do curso de Administração de Empresas (FAGEN/UFU).

5 Aluno do curso de Administração de Empresas (FAGEN/UFU).

6 Aluno do curso de Administração de Empresas (FAGEN/UFU). 


\title{
INFORMATIONAL BEHAVIOR: A STUDY WITH UNDERGRADUATE BUSINESS STUDENTS
}

\begin{abstract}
It is important to study the use and the users of information in order to understand the information needs of individuals and to evaluate if the services offered meet these needs adequately, as well as to know if the resources are being used properly. Despite the relevance of this issue, there is an opportunity for new studies on this subject, with undergraduate students in the field of management. Therefore, the aim of this paper is to analyze the information behavior of undergraduate business students from a public university located in the state of Minas Gerais / Brazil. The qualitative approach was adopted and the data was collected through semi structured interviews. The main results indicate that information sources such as books, internet, teachers, and colleagues are important components of the information behavior of the students that participated in the study. The most useful information source highlighted by the students is the internet, but the internet was also considered as the less trustworthy source. Our results also indicated that the students' information needs are related mainly with their academic and professional activities. These results are relevant and can ground educational/pedagogic policies of the universities, especially when we consider that skills to assimilate new information represent a desirable characteristic of graduates in the management field.
\end{abstract}

Keywords: Information. Knowledge. Information Needs.

\section{INTRODUÇÃO}

A informação é um recurso relevante para que os indivíduos possam tomar decisóes, resolver problemas, realizar seu planejamento e também buscar o seu desenvolvimento. Diante dessa relevância, governos e grupos econômicos tem voltado a atenção para os processos relacionados com a informação (MARCHIORI, 2002).

À medida que as organizaçóes têm se tornado mais intensivas em informação e o conhecimento tem sido percebido como uma nova base para a competitividade, a competência informacional tem se tornado um dos principais ativos das organizaçóes (HWANG, 2011). Essa competência informacional está no cerne do aprendizado ao longo da vida e compreende as habilidades para buscar, avaliar, usar e comunicar a informação de forma ética e efetiva (FARIAS; VITORINO, 2009; XAVIER, 2013).

Apesar de tais habilidades serem importantes para profissionais de diversas áreas, as mesmas são particularmente relevantes para profissionais da área de Administração, já que dentre as atribuiçôes desses profissionais estáo a tomada de decisóes, a resolução de problemas organizacionais e a gestáo do conhecimento (XAVIER, 2013).

Visando contemplar essas habilidades, as Diretrizes Curriculares Nacionais do Curso de Graduação em Administração (CNE/CES, 2005) indicam a aptidão para assimilar novas informaçóes como uma das características desejáveis dos egressos e apontam para a necessidade de se abordar conteúdos relacionados às tecnologias da informação e da comunicação nos projetos pedagógicos.

Sabe-se que no âmbito dos cursos de graduação, os estudantes de Administração podem utilizar diferentes fontes para buscar informaçōes e atender à demanda de disciplinas. Conhecer as necessidades informacionais e o comportamento de busca de informaçóes desses alunos torna-se, portanto, relevante a fim de direcionar os bibliotecários, professores e coordenadores de curso para que eles ofereçam serviços e instrução apropriados, moldados a essas necessidades informacionais (CATALANO, 2013). 
Embora pesquisas anteriores já tenham examinado o comportamento informacional de estudantes de diversas áreas tais como humanas, engenharia, artes, medicina e ciências sociais (HE et al., 2012; NWAGWU, 2012; BRENNAN, 2014), parece haver espaço para a análise do comportamento informacional de alunos da área de negócios, especificamente de estudantes do curso de Administração. De acordo com Martinez-Silveira e Oddone (2007), as necessidades informacionais são subjetivas e muitas vezes estão relacionadas às atividades profissionais de cada indivíduo. O estudo de Catalano (2013) identificou que alunos de diferentes cursos acessam fontes diferentes de informação. Estudantes das áreas de humanas e artes tendem a utilizar mais os serviços de bibliotecas para buscar informaçóes do que estudantes de engenharia e ciências físicas, por exemplo (WHITMIRE, 2002; NWAGWU, 2012).

Nesse contexto, o presente artigo tem como objetivo analisar o comportamento informacional dos alunos do curso de Administração matriculados em uma Universidade Pública do Estado de Minas Gerais. Conforme apontado por Steinerová e Susol (2005, p. 139), o estudo sobre o comportamento informacional dos indivíduos "[...] pode contribuir para o desenvolvimento de novos sistemas e ferramentas para organizaçáo do conhecimento e uso da informação, tanto nos âmbitos acadêmicos e científicos quanto nas organizações”.

Os professores ministram o conteúdo em sala de aula, elaboram atividades baseadas em livros-textos, em listas de exercícios, recomendam trabalhos em grupos, além de atividades complementares e atividades avaliativas. Entretanto, as necessidades informacionais dos alunos não necessariamente se limitam ao que é discutido em sala de aula, uma vez que eles podem buscar conteúdo auxiliar para manterem-se informados. Desta forma, este estudo mostra-se relevante pelo seu potencial de evidenciar características que são consideradas pelos estudantes da área de negócios como determinantes na obtenção de informaçóes ao longo de seu curso de graduação.

Estruturalmente, esse artigo está dividido em quatro seções, além dessa introdução. A segunda seção trata do referencial teórico, abordando tanto conceitos teóricos relacionados à Ciência da Informação e ao Comportamento Informacional, quanto estudos anteriores sobre o tema. A terceira seção descreve os procedimentos metodológicos, que é seguida da análise de resultados. $\mathrm{Na}$ quinta e última seção são apresentadas as consideraçóes finais.

\section{REFERENCIAL TEÓRICO}

\subsection{Informaçáo e Ciência da Informação}

Para Barreto (1994), a informação é algo que sintoniza o mundo e que está presente na evolução da história da humanidade. Segundo o autor, a informação funciona como um modificador da consciência e quando é bem assimilada produz conhecimento e traz benefícios ao desenvolvimento do indivíduo. Laudon e Laudon (2010, p. 12) definem o termo informação como "[...] dados apresentados em uma forma significativa e útil para os seres humanos". Portanto, a informação deve comportar um elemento de sentido e graças ao sistema de símbolos ela pode ser transmitida na forma escrita, oral ou audiovisual a seres conscientes (LE COADIC, 1996). 
A velocidade de transmissão da informação é um dos marcos da chegada do século XXI, no qual o mundo globalizado é chamado de Sociedade da Informação ou Sociedade do Conhecimento. Graças ao progresso tecnológico, o processo comunicacional foi facilitado, ou seja, a transmissão e o armazenamento de informação ficaram mais rápidos e com maior facilidade de recuperação (SILVA; CUNHA, 2002).

Visando acompanhar esse desenvolvimento da sociedade da Informação, surgiu a Ciência da Informação, que tem como objetivo estudar as propriedades da informação e os processos de sua construção, comunicação, armazenamento e uso (LE COADIC, 1996). Trata-se de uma ciência multidisciplinar que envolve diversas áreas tais como a psicologia (comportamentos de comunicação e representação do conhecimento), a linguística (semiótica, morfossintaxe), a informática (bancos de dados, recuperação da informação), a eletrônica e telecomunicaçóes (redes, correio eletrônico), a economia (comercialização da informação, sociedade da informação) e a matemática (lógica difusa, processos markovianos etc.) (LE COADIC, 1996).

Estudos na área da Ciência da Informação tem focado principalmente na busca de informações como parte do comportamento informacional humano (STEINEROVÁ; SUSOL, 2005; HEINSTROM; SORMUNEN; KAUNISTO-LAINE, 2014). De acordo com Le Coadic (1996), estudos sobre usos e usuários da informação são importantes para que se compreenda as razóes que levam as pessoas a buscarem informaçōes, para que se conheça as suas necessidades informacionais, para que seja avaliada até que ponto os serviços oferecidos respondem a essas necessidades e para saber se está sendo feito um bom uso dos recursos oferecidos.

\subsection{Comportamento Informacional}

O comportamento informacional pode ser definido como todo comportamento humano relacionado com as fontes de informaçáo, incluindo tanto a busca ativa da informação e a comunicação face-a-face com outras pessoas quanto a recepção passiva de informação por meio de anúncios televisivos, por exemplo (WILSON, 2000). Fisher e Julien (2009, p. 1) apontam que "o comportamento informacional se concentra nas necessidades informacionais dos indivíduos e em como eles procuram, gerenciam, transmitem, e utilizam informações, tanto propositadamente quanto passivamente, nos papéis variados que compreendem o seu cotidiano". No contexto de Sistemas de Informação, o comportamento de busca de informações é constituído pelas interações do indivíduo com o sistema e envolve fatores mentais, ao fazer o julgamento da relevância das informaçōes obtidas (WILSON, 2000).

A necessidade, uso, busca e transferência de informaçóes são alguns conceitos do comportamento informacional (LE COADIC, 1996, GASQUE; COSTA, 2003). Ter consciência sobre a necessidade de informação é o primeiro passo. Posteriormente, o processo de busca pela informação depende de fatores tais como a acessibilidade, a confiança e a relevância das fontes de informação (BRUM; BARBOSA, 2009). 
Existem diversas fontes de informação que vão desde fontes tradicionais (dicionários, livros etc.) e pessoas até recursos baseados na internet. Essas fontes são selecionadas de acordo com as escolhas subjetivas dos usuários (BRUM; BARBOSA, 2009).

No que se refere às fontes tradicionais, Almirante e Ramalho (2007) apontam que as bibliotecas assumem um papel muito importante na geração de conhecimento e devem suprir as necessidades informacionais de seus usuários. As autoras também destacam que, com o avanço da tecnologia surgiram bibliotecas virtuais e eletrônicas, o que provocou mudanças significativas na forma de disponibilizar informaçóes para os usuários.

Com relação à internet, Menou (2010) destaca que a mesma integra não apenas fontes de informação e meios de comunicação, mas também comportamentos. Segundo o autor, além de buscar as informaçóes de que necessitam, os usuários da internet agem com base nesta informação, por exemplo, fazendo compras, realizando transações, conhecendo pessoas, etc. A internet também tem fornecido muitas opções para a interação social, permitindo assim a busca e o compartilhamento de conhecimento (MILLS; KNEZEK; KHADDAGE, 2014).

Vale ressaltar, ainda, que o conteúdo acessado na internet pode ter diferentes formatos, como textos acadêmicos, notícias, blogs, legislaçôes específicas, conteúdo com áudio e / ou áudio e vídeo, ambientes virtuais de aprendizagem, páginas de órgãos reguladores, etc.

Sobre as pessoas, Nwagwu (2012) ressalta que existe uma expectativa natural de que, em grande parte das atividades humanas, outros seres humanos sejam considerados a opção mais fácil para a busca de informaçôes. De acordo com Fisher e Julien (2009), que elaboraram um estado da arte sobre comportamento informacional, as fontes de informaçáo dominantes na literatura são as interpessoais com ênfase no papel das redes sociais e a internet considerando-se suas aplicaçôes tanto síncronas quanto assíncronas.

Assim, a internet pode se apresentar como uma ferramenta que também se ajusta a diferentes características dos indivíduos que realizam determinados tipos de pesquisa, em virtude da diversidade de formatos nos quais as informaçōes podem estar disponíveis.

\subsection{Estudos anteriores}

Diante da relevância de se analisar os processos relacionados à informaçáo, especialmente em contextos acadêmicos, pesquisadores de diversos países tem realizado estudos visando conhecer o comportamento informacional de estudantes. Conforme apontado por Tury, Robinson e Bawden (2015), o comportamento informacional de estudantes tem sido um dos temas mais estudados dentro de todo o campo da investigaçáo do comportamento informacional, havendo muitos dados empíricos e modelos propostos.

A pesquisa realizada por He et al. (2012) com alunos dos Estados Unidos e da China, por exemplo, teve como objetivo identificar a opinião de estudantes de graduação sobre a importância de recursos baseados na internet para realizar atividades acadêmicas. A pesquisa foi realizada com alunos das áreas de humanas, ciências, medicina e saúde, ciências sociais e engenharia. Os resultados mostraram que máquinas de busca e recursos que facilitam o compartilhamento de documentos são comumente utilizados pelos alunos. $\mathrm{O}$ estudo também mostrou que existem diferenças no comportamento informacional dos alunos da 
China em relação aos alunos dos Estados Unidos. Enquanto os alunos chineses recorrem mais a recursos tradicionais (dicionários, livros, artigos etc), os alunos americanos recorrem mais a recursos online. Essas diferenças indicam que ao se analisar o comportamento informacional de indivíduos é necessário levar em consideração a cultura na qual estão inseridos.

Além da dimensão cultural, outro aspecto que deve ser considerado se refere às características individuais dos estudantes, conforme observado por Heinstrom, Sormunen e Kaunisto-Laine (2014). A pesquisa foi desenvolvida com o objetivo de analisar o papel da personalidade e da abordagem de estudo no comportamento informacional de estudantes do ensino médio. De acordo com os resultados, tanto a personalidade quanto a abordagem de estudo influenciam os diferentes aspectos do comportamento informacional dos estudantes desde a busca por informaçóes até o uso dessas informaçóes.

O estudo de Catalano (2013) com alunos da pós-graduação de diversas áreas identificou que a maioria dos estudantes consulta a internet em primeiro lugar ao começar sua pesquisa e que os estudantes de doutorado são mais inclinados a também consultar seus orientadores. Segundo os autores, as pessoas (docentes, bibliotecários e amigos) desempenham um papel importante em ajudar os alunos no início de suas pesquisas.

De acordo com o estudo de Baro, Onyenania e Osahen (2010), os alunos de graduação geralmente realizam pesquisas para obter informaçóes acadêmicas $(93,2 \%)$, informaçóes pessoais $(4,0 \%)$, e informaçóes sobre esportes $(2,8 \%)$. As respostas revelaram que os estudantes de graduaçáo precisam de informaçóes acadêmicas para escrever seus trabalhos, apresentar seminários e preparar-se para os seus exames e testes.

Com foco em alunos da educaçáo à distância, o estudo de Tury, Robinson e Bawden (2015) revelou que o nível e o objeto de estudo influenciam o comportamento informacional desses alunos. Com relação às fontes de informação, a facilidade e rapidez de acesso são os aspectos que os alunos consideram como mais relevantes.

Estes aspectos também afetam a preferência do formato de leitura preferido pelos estudantes (MIZRACHI, 2015). O estudo de Mizrachi (2015) com alunos de graduação de uma universidade dos Estados Unidos apontou que embora os alunos prefiram materiais impressos em relação aos eletrônicos para fins de aprendizagem, fatores tais como acessibilidade, custo e complexidade costumam afetar suas escolhas e seus comportamentos. Acessar meios eletrônicos é mais conveniente e envolve menos custos, por exemplo.

Brennan et al. (2014) realizaram um estudo com médicos e estudantes de medicina. Os resultados mostraram que os principais fatores que influenciam a escolha da fonte de informação são facilidade de acesso e qualidade da informação. Já pesquisa de Stokes e Urquhart (2015) com estudantes de enfermagem identificou que no início os alunos buscam apenas uma quantidade pequena de informaçóes que seja suficiente para ter conhecimento sobre determinado tema. Só mais adiante, os alunos buscam aprofundar suas pesquisas.

O estudo de Nwagwu (2012) com estudantes de artes e de engenharia apontou que os estudantes de ambas as áreas consultam fontes interpessoais. Esse resultado se deve ao fato de o perfil de interaçáo interpessoal de estudantes ser geralmente muito elevado. 
$\mathrm{Na}$ área da negócios, Xavier et al. (2013), analisaram a percepção de concluintes de um curso de Administração sobre o seu nível de competência informacional. Os resultados mostraram que dentre as categoria analisadas, a categoria que apresentou a maior média se refere à capacidade de utilizar a informação e a que apresentou a menor média foi a categoria que se refere à classificação e organização das informações.

Byrne e Bates (2009) investigaram o comportamento informacional de estudantes de um curso de ensino à distância da área de negócios na Irlanda. O estudo constatou que dentre os recursos utilizados pelos alunos para busca de informaçóes, houve uma preferência geral por recursos eletrônicos tais como as máquinas de busca e a biblioteca eletrônica. O estudo também identificou que os estudantes dependem significativamente de seus professores no que diz respeito à aquisição de informaçóes sobre os seus cursos. Outra constatação foi a de que a colaboraçáo no que diz respeito à partilha de informaçóes entre professores e alunos e entre alunos é uma importante faceta do comportamento informacional dos alunos pesquisados.

A revisão da literatura indica que apesar da grande quantidade de estudos relacionados ao comportamento informacional de estudantes, pouca atençáo tem sido dada ao comportamento de estudantes da área de negócios, especialmente no Brasil, havendo uma carência de estudos com foco nesses estudantes. Esse artigo visa suprir essa lacuna encontrada na literatura existente por meio da análise das necessidades informacionais e do comportamento de busca por informaçóes dos estudantes de um curso de Administração.

\section{METODOLOGIA}

A fim de atingir o objetivo dessa pesquisa foi adotada a abordagem qualitativa, que de acordo com Godoy (1995) é o tipo de investigação mais adequado quando se busca compreender um fenômeno como um todo, na sua complexidade. Quanto aos objetivos, trata-se de uma pesquisa descritiva, pois busca descrever características e propriedades do grupo ou realidade pesquisada (RAMPAZZO, 2005).

A coleta de dados foi realizada por meio de entrevistas semiestruturadas com alunos matriculados em diferentes períodos do curso de Administração de uma Universidade Pública localizada no Estado de Minas Gerais, selecionados por conveniência. No método de seleção por conveniência, os indivíduos são escolhidos pela sua disponibilidade e acessibilidade (SAMPIERI; COLLADO; LUCIO, 2013). Ressalta-se que a participação dos estudantes foi voluntária. A quantidade de alunos entrevistados foi definida durante o processo de coleta dos dados, quando houve a saturaçáo das respostas, ou seja, quando os autores identificaram que, por não haver grandes diferenças entre as respostas dos alunos, não surgiriam percepçôes adicionais. Esta saturação foi alcançada com 12 entrevistas.

A entrevista semiestruturada foi escolhida porque nela o entrevistado é estimulado a discorrer mais sobre o assunto proposto. A entrevista tenta simular uma conversa informal, deixando o entrevistado mais a vontade para que ele forneça as informações necessárias para cumprir os objetivos da pesquisa (BONI; QUARESMA, 2005). As entrevistas foram realizadas com base em um roteiro contendo perguntas sobre as necessidades informacionais dos alunos, as fontes de informaçóes utilizadas por eles a utilidade e a confiabilidade dessas 
fontes na percepção dos mesmos. Havia perguntas específicas sobre o uso da biblioteca universitária, da internet, de revistas e jornais e de fontes interpessoais.

As entrevistas foram gravadas com consentimento dos participantes, transcritas e analisadas por meio da técnica de Análise de Conteúdo (BARDIN, 1977). Esse tipo de análise trabalha com materiais escritos (transcriçóes das entrevistas, documentos etc.) e pode ser visto como um conjunto de técnicas que permitem a inferência de conhecimentos a partir do conteúdo desses materiais (BARDIN, 1977). A análise foi realizada com auxílio do programa $\mathrm{NVivo}^{\circ}$ (QSR International), no qual as unidades de significado foram codificadas e agrupadas em categorias relacionadas aos objetivos do trabalho.

\section{ANÁLISE DOS RESULTADOS}

Conforme mencionado anteriormente, foram entrevistados 12 alunos matriculados no curso de graduação em Administração de uma Universidade Pública localizada no Estado de Minas Gerais. Dos 12 alunos entrevistados, 8 eram do sexo masculino e 4 eram do sexo feminino. Todos os entrevistados eram solteiros, 10 trabalhavam e a idade dos participantes variava de 17 a 24 anos.

Da análise do conteúdo das entrevistas, pôde-se extrair seus principais pontos chaves que foram codificados e então agrupados nas seguintes categorias: C1 - Necessidades Informacionais; C2 - Fontes Tradicionais de Informaçấo; C3 - A Internet como fonte de Informações; C4 - Pessoas como Fonte de Informaçôes. Essas categorias são apresentadas nas seçôes 4.2.1 a 4.2.4.

\subsection{Necessidades Informacionais}

Com base nos dados coletados, observou-se que as principais necessidades informacionais que levam os estudantes a buscarem informaçôes estão relacionadas com as suas atividades acadêmicas e profissionais. Alguns alunos também citaram a necessidade de se manterem informados sobre os acontecimentos e sobre esportes. Esses resultados estáo em linha com os resultados encontrados por Baro, Onyenania e Osahen (2010). Os trechos das entrevistas abaixo sumarizam as necessidades informacionais dos estudantes entrevistados.

\footnotetext{
E2: Eu uso mais [a internet] para ver notícia de esporte, do meu palmeiras, e para pesquisar coisas da universidade e algumas vezes para meios de trabalho, pois eu trabalho todo dia, e uso bastante o e-mail, pesquisa de clientes e fornecedores.
}

E3: Uso [a internet] com a finalidade de manter o contato com amigos e estudar e também saber mais informações sobre o que tá acontecendo no mundo.

E8: É, procuro pesquisar mais [...] algo que vai agregar um pouco de conhecimento, tanto no curso, quanto na vida profissional.

E9: Sempre me cadastro em sites, páginas que se referem a Administração, pra ficar sempre por dentro de tudo. 
A maioria dos alunos considera importante buscar informações para complementar os estudos com materiais além dos utilizados pelos professores em sala de aula, conforme pode ser visto nos trechos de entrevistas abaixo.

E1: Busco outras referências também. Porque às vezes podemos encontrar materiais mais didáticos fora do que o professor passou.

E3: Busco outras referências também. Pra adquirir um conhecimento a mais, e tentar me diferenciar dos outros, sabendo de conteúdos que talvez eles ainda náo saibam.

E6: Porque acho que o material do professor, apesar de ser bom assim, é muito pouco, eu acho que as vezes você tem que ir um pouco além. Assim, por exemplo um livro, alguma coisa que ele indicou.

Conclui-se por meio das entrevistas que os alunos apresentam um comportamento ativo na busca por informaçóes. Eles não recebem informações apenas de forma passiva pela televisão ou por meio das aulas. Ao contrário, eles demonstraram interesse em se manterem informados sobre o curso e sobre a área em que atuam, e a internet se mostra como uma ferramenta relevante neste processo.

\subsection{Fontes Tradicionais de Informaçóes}

Quando perguntados sobre as fontes de informação preferidas, dentre as fontes tradicionais mais citadas estão os livros. Eles também foram citados como a fonte mais confiável para obtenção de informações. De acordo com os entrevistados, eles são escritos por pessoas com reconhecimento acadêmico e isso dá maior credibilidade para as informaçóes neles contidas:

E6: Pra mim... sei lá, acho que livro e revista acadêmica, esse tipo de coisa assim um pouco mais sério, um pouco mais embasado, é melhor.

E11: Para escrever um livro acredito que é bem mais difícil, é mais trabalhoso e desgastante. Por isso tem, vamos dizer, um maior esforço e pesquisas do autor. Por isso a credibilidade.

As respostas também mostraram que frequentar a biblioteca da universidade faz parte da rotina de estudos da maioria dos entrevistados, mesmo alguns alunos nunca tendo a visitado. Os alunos a frequentam tanto para realizar empréstimos de livros quanto para utilizá-la como espaço de estudo, pois ela oferece um ambiente calmo e propício para o desenvolvimento de atividades acadêmicas. O tempo que os entrevistados gastam na biblioteca varia de 30 minutos a 4 horas dependendo da necessidade.

E2: Eu frequento uma vez por semana ou duas, dependendo da quantidade de trabalho que eu tenho.

E4: Geralmente entre duas ou três vezes por mês. Na média eu gasto de duas a três horas na biblioteca. 
E5: Vou quando é necessário para mim. Eu vou muito (risos) porque são muitos e muitos trabalhos.

Quando questionados sobre o uso da biblioteca em época de greve, os alunos que tem o costume de frequentá-la usam meios alternativos, principalmente a internet, para estudar ou fazer trabalhos.

E3: Aí eu procuro na internet, ou peço ajuda aos meus amigos, fazendo grupos de estudos.

E5: Se porventura estiver fechada e houver trabalhos em grupo para fazer, faço através da internet e rede social.

E6: Ah eu... ou vou na biblioteca da cidade, da biblioteca municipal lá, sento lá e estudo, quando eu preciso de um livro, e quando não precisa, é em casa mesmo, utilizando a internet.

Quanto aos alunos que mantém a prática de leitura de jornais e revistas, alguns consideram que informaçóes presentes nesses meios, tais como as notícias mais recentes e a cotação do dólar, por exemplo, sáo imprescindíveis para começar o dia. Os telejornais também foram citados como fontes de informação. Um dos estudantes apontou a leitura de revistas como uma forma de entretenimento.

E8: É sempre pra agregar né. São... geralmente são periódicos, que vem de mês em mês, de semana em semana [...] economia, questão de cotação do dólar.

E9: Sim, gosto de ler bastante jornais pelo fato de ver as notícias, os assuntos mais comentados e revistas pra ver o que tem de novo e ficar por dentro dos assuntos.

Já alguns alunos não sentem necessidade ou não possuem tempo para buscar informaçóes nessas fontes. Um estudante mencionou que a estimulação familiar pode estar envolvida na falta do hábito de ler jornais, enquanto outro disse que náo costuma ler o jornal assinado pela família.

E2: Pela falta de tempo e também de interesse, mesmo sabendo que é errado, eu não tenho o costume de ler, só vejo jornal mesmo.

E3: Não, não criei, acho que para ter esse hábito, tem que ser cultivado desde pequeno, e como não me influenciaram, não leio jornais nem revistas. Mas acho isso muito importante, principalmente na área de Administração, porém eu não faço o mesmo.

E11: Em casa tem um jornal que minha família assina, mas é uma vez ou outra que eu olho.

Com base na análise das fontes tradicionais de informaçóes, percebe-se que os livros e as revistas acadêmicas assumem posição especial no que se refere à percepçáo de confiabilidade atribuída aos alunos. Estas fontes estáo mais relacionados com a formação acadêmica, o que corrobora com o papel assumido pelas bibliotecas na geraçáo de conhecimento de seus usuários (ALMIRANTE; RAMALHO, 2007). Por outro lado, fontes de informaçóes que 
são atualizadas com maior periodicidade (como semanal ou diária) ainda não estão no foco da maior parte dos respondentes.

\subsection{A Internet como fonte de Informaçóes}

Todos os entrevistados utilizam a internet pelo menos uma vez ao dia, seja para estudar, trabalhar, olhar as notícias, entretenimento ou apenas para checar e-mails. Dentre os recursos baseados na internet mais utilizados pelos alunos estão os sites de busca e as redes sociais. Um dos alunos, quando questionado sobre o tempo diário uso da internet, disse que fica conectado 24 horas por dia. Seguem alguns comentários dos entrevistados sobre a utilização da internet:

E2: Como eu trabalho com turismo, eu leio bastante jornais de turismo na internet.

E4: Geralmente procuro me informar sobre esses assuntos na internet, artigos e até mesmo em mídias sociais, que além de estar em crescimento, as considero como boas fontes de informações.

E6: Seria na internet, porque geralmente quando eu vou fazer uma pesquisa, vou fazer alguma coisa relacionada sobre um trabalho da faculdade, a internet é o primeiro lugar que, que eu procuro. Lá tem um... uma informação especial.

E7: Ah, pra tudo, pra estudar, redes sociais, pra tudo.

Sobre as vantagens da internet em relação às outras fontes, os alunos citaram a abrangência de conteúdo e a facilidade e rapidez para obtenção de informaçóes. A facilidade de acesso também foi apontada por Mizrachi (2015), como uma das razóes que levam os estudantes a optarem pelos meios eletrônicos.

E1: Eu considero [a internet] uma fonte de pesquisa bem mais rápida... e flexível.

E12: Eu acho que a internet [é mais útil] porque ela abrange mais conteúdo do que as vezes um livro. Então com a internet você consegue procurar fontes diferentes, ter mais variedade e sobre diferentes assuntos. Às vezes livro é mais específico.

E3: Porque ela é mais ampla, ela é mais fácil de pesquisar.

Apesar de ter sido citada como a fonte mais utilizada para pesquisas, a internet também foi apontada pelos alunos como a fonte menos confiável.

E2: Então a menos confiável para mim é a internet, pois pode ter muitas coisas que... que não tem nenhuma relevância, ou que não tem procedência nenhuma.

E6: ah qualquer um pode colocar qualquer coisa na internet, então não é confiável. [...] Porque como eu falei, às vezes você precisa de uma informação mais séria, uma informação mais confiável e que a internet náo vai te proporcionar com cem por cento de certeza. 
Os resultados para esta categoria complementam as observaçóes da categoria anterior, pois, embora as fontes tradicionais de informação (jornais e revistas) no formato impresso, especialmente com maior atualização periódica (diária ou semanal), parecem não despertar muito o interesse dos alunos entrevistados, o conteúdo eletrônico, que também pode ser objeto de atualização periódica, está dentro das opçóes que eles consideram quando vão buscar informações sobre o curso e informaçóes para fins profissionais. Isso reforça o importante papel que a internet assume como fonte de informação e meio de comunicação (MENOU, 2010).

Embora alguns alunos reconheçam também as limitaçóes de algumas fontes disponíveis na internet, em relação à sua confiabilidade, ressalta-se a relevância de que os alunos sejam esclarecidos sobre potenciais prejuízos que poderiam ser decorrentes do uso de informaçóes que não possuem fundamentação. Contudo, caso o aluno já adote a prática de se informar nas fontes mais adequadas a respeito de assuntos relacionados à gestão, essa prática pode ter efeitos positivos em sua performance futura enquanto gestor de organizaçóes.

\subsection{Pessoas como fonte de informaçóes}

Com relação à obtenção de informações com outras pessoas, familiares foram citados por apenas um aluno, enquanto os amigos e professores foram bastante citados por todos os entrevistados. Alunos veteranos também foram citados por um dos entrevistados como uma de suas fontes de informação. Alguns trechos que falam sobre os principais contatos que ajudam na obtenção da informação são:

E2: Ah, alguns professores, eu tenho contato e o que eu preciso eu pergunto pra eles, algumas indicaçôes de livros e etc.

E4: Os professores e os meus amigos. Como por exemplo, às vezes eu estudo em grupo para realizar os trabalhos.

E10: Professores e colegas de grupo... Sala.

O estudo em grupo foi apontado como sendo eficaz porque existe muita eficiência no compartilhamento de ideias devido aos debates. Porém essa forma de estudo foi apontada como problemática por alguns dos entrevistados, visto que existe certa dificuldade de organização para que tudo ocorra bem sem que alguns conflitos que possam surgir prejudiquem o andamento do grupo. Os trechos abaixo mostram as opinióes sobre estudar em grupo.

E1: Eu acredito, que os trabalhos em grupo são muito importantes, porque geram debate e isso soma muito no ensino do aluno.

E5: Depende, na maioria das vezes eu opto por estudar sozinho, mas de contrapartida às vezes opto por estudar em grupo, a fim de compartilhar conhecimento. 
E3: Olha... trabalho em grupo, as vezes eu não gosto, porque as vezes você quer fazer de uma maneira e a outra pessoa que fazer do jeito dela, e acaba não aceitando, e essa outra pessoa que não aceita, acha que ela só tá certa, entâo você acaba se limitando a sua ideia.

E9: Acho que os trabalhos em grupo auxiliam na convivência e preparação, porque quando formarmos vamos lidar com várias pessoas e é preciso aprender a trabalhar em grupo pra ser uma boa profissional.

Percebe-se por meio das entrevistas que as relaçóes com pessoas que estão presentes no meio acadêmico, especialmente professores e colegas de sala, configuram-se como um componente relevante do comportamento informacional dos alunos entrevistados. Esses resultados estão em consonância com os estudos de Byrne e Bates (2009), Fisher e Julien (2009) e Catalano (2013).

Além disso, observando-se que o estudo de Fisher e Julien (2009) ressaltou a ênfase no papel das redes sociais como um recurso interpessoal para que os indivíduos possam buscar informaçóes, destacam-se novas oportunidades de pesquisa no que se refere ao papel das redes sociais no comportamento informacional dos alunos do curso de Administração. Esta oportunidade de pesquisa é ainda reforçada pelos resultados deste estudo, uma vez que as atividades em grupo foram apontadas como relevantes para o desenvolvimento de habilidades de comunicação e compartilhamento de ideias.

\section{CONSIDERAÇÓES FINAIS}

Este artigo teve como objetivo analisar o comportamento informacional dos alunos do curso de Administração matriculados em uma Universidade Pública do Estado de Minas Gerais. Os resultados revelaram que as principais razóes que levam os alunos a buscar informaçóes são as acadêmicas e as profissionais. Dentre as fontes de informação mais utilizadas pelos alunos estão os livros e a internet. A biblioteca universitária também assume um papel importante na vida acadêmica da maior parte dos alunos. Enquanto alguns alunos nunca frequentaram a biblioteca, a maioria dos entrevistados disse ter o hábito de frequentar a biblioteca em média uma vez por semana.

A internet trouxe novas possibilidades de encontrar qualquer tipo de informação e também de se comunicar com amigos e conhecidos. Assim a internet foi considerada pelos participantes da pesquisa como a fonte mais útil, já que a mesma pode ser utilizada em qualquer lugar e possui muitas informaçóes. Essa fonte também possui relevância para os administradores, devido à possibilidade de consultas em tempo real a notícias setoriais específicas, bem como notícias econômicas, de uma maneira geral. Pode-se ter acesso digital a jornais de grande circulação, cotaçôes de diferentes moedas e comportamento de variáveis como taxas de juros, o que mostra-se como informação que apoia o processo de decisão na gestão das organizaçóes.

Entretanto, embora a internet tenha facilitado a vida acadêmica dos alunos melhorando a comunicação e a obtenção de informações, na visão dos mesmos nem todo conteúdo postado na internet é confiável. Conforme os resultados da pesquisa, existe uma percepção por parte dos respondentes de que qualquer indivíduo pode postar conteúdo na internet, o que implica no comprometimento da confiabilidade do conteúdo acessado, dependendo do 
sítio eletrônico no qual uma determinada informação encontre-se publicada. Ainda assim, essa tem sido a principal fonte de informaçóes utilizada pelos alunos.

A internet também tem servido como meio de contato entre os estudantes, já que a maioria deles trabalha e na maior parte do tempo não estáo presentes na universidade. Os relacionamentos interpessoais, especialmente entre professores e alunos, bem como entre os próprios alunos, se mostraram um componente importante do comportamento informacional dos estudantes entrevistados, o que abre oportunidades para novos estudos incluírem, por exemplo, o papel das redes sociais no comportamento informacional dos estudantes universitários.

Como já apontado anteriormente, no desempenho de suas funçôes, o administrador necessita de informaçóes para a tomada de decisão e gestáo das entidades às quais estiver vinculado. Estudar o comportamento informacional dos alunos do curso de administração torna-se relevante, por evidenciar as principais fontes que atendem à demanda informacional dos estudantes universitários que pretendem obter uma graduação na área de negócios. Ao identificar as principais fontes, e também evidenciar que os próprios estudantes percebem limitaçóes e necessidade de cautela em relação à algumas fontes (como é o caso de determinados conteúdos disponíveis na internet), abrem-se oportunidades para novos estudos com o objetivo de avaliar o comportamento informacional dos alunos ao longo do tempo, inclusive após alcançarem o status de egressos do curso.

Ademais, os resultados revelam a importância de os professores reforçarem aos alunos as limitaçóes decorrentes do uso de fontes pouco conhecidas para as atividades de estudos acadêmicos. Entende-se que haja espaço para que este tema (confiabilidade das fontes consultadas) seja abordado em atividades acadêmicas que envolvam a pesquisa de fontes complementares às indicadas pelos professores. Esse ponto pode também ser explorado em novas pesquisas sobre o assunto.

Destaca-se que diferentemente da maioria das pesquisas anteriores que adotaram a abordagem quantitativa, nessa pesquisa foi adotada a abordagem qualitativa, tendo sido realizadas entrevistas semiestruturadas, o que permitiu a análise do comportamento informacional dos alunos de forma mais profunda.

Como limitação do estudo pode ser apontado o fato de o mesmo ter sido realizado com estudantes de apenas uma instituição de ensino pública de Minas Gerais, o que pode comprometer a generalização dos resultados. Adicionalmente, o estudo foi realizado considerando apenas o momento no qual o estudante encontrava-se, não evidenciando potencias variaçóes (ou consistência) do comportamento informacional ao longo do tempo.

Como estudos anteriores indicaram a importância de se considerar a influência da diversidade cultural no comportamento informacional, sugere-se como estudo futuro uma expansão dessa investigação para diferentes regióes do Brasil, a fim de se analisar a influência das diferenças culturais e regionais no comportamento informacional de estudantes. 


\section{REFERÊNCIAS}

ALMIRANTE, C. M.; RAMALHO F. A. Buscas e usos da informação: Um estudo com alunos do curso de Administração da UFPB. Biblionline, v. 3, n.2, p. 1-18, 2007.

BARDIN, L. Análise de conteúdo. Lisboa: Ediçôes 70, 1977.

BARO, E. E., ONYENANIA, G. O.; OSAHENI, O. Information seeking behaviour of undergraduate students in the humanities in three universities in Nigeria. South-African Journal of Library and Information Science, v. 76, n. 2, p. 109-117, 2010.

BARRETO, A. de A. A questão da informação. Sáo Paulo em Perspectiva, v. 8, n. 4, p. 1-7, 1994.

BYRNE, S.; BATES, J. Use of the university library, elibrary, VLE, and other information sources by distance learning students in University College Dublin: Implications for academic librarianship. New Review of Academic Librarianship, v. 15, n. 1, p. 120 $141,2009$.

BONI, V.; QUARESMA, S. J. Aprendendo a entrevistar: como fazer entrevistas em Ciências Sociais. Revista Eletrônica dos Pós-Graduandos em Sociologia Política da UFSC, v. 2, n. 1, p. 68-80, 2005.

BRENNAN, N. et al. Qualified doctor and medical students' use of resources for accessing information: what is used and why? Health Information \& Libraries Journal, v. 31, p. 204-214, 2014.

BRUM, M. A. C.; BARBOSA, R. R. Comportamento de busca e uso da informaçáo: um estudo alunos participantes de empresas juniores. Perspectivas em Ciência da Informaçáo, v. 14, n.2, p.52-75, 2009.

CATALANO, A. Patterns of graduate students' information seeking behavior: a metasynthesis of the literature. Journal of Documentation. v. 69, n. 2, p. 243-274, 2013.

CNE/CES. Resoluçáo CNE/CES n ${ }^{\circ}$ 4, de 13 de julho de 2005. Institui as Diretrizes Curriculares Nacionais do Curso de Graduação em Administração, Bacharelado, e dá outras providências. Disponível em: <http://portal.mec.gov.br/component/content/ article?id=12991> Acesso em: 25. abr. 2016.

FARIAS, C. M.; VITORINO, E. V.; Competência informacional e dimensóes da competência do bibliotecário no contexto escolar. Perspectivas em Ciência da Informaçáa, v. 14, n. 2, p. 2-16, 2009.

FISHER, E. K.; JULIEN, H. Information Behaviour. Annual Review of Information Science and Technology, v. 43, n. 1, p. 1-73, 2009. 
GASQUE, K. C. G.D; COSTA, S. M. de S. Comportamento dos professores da educação básica na busca da informação para formação continuada. Ciência da Informação, v. 32, n.3, p. 54-61, 2003.

GODOY, A. S. Introdução à pesquisa qualitativa e suas possibilidades. Revista de Administraçáo de Empresas, v. 35, n.2, p. 57-63, 1995.

HE, D. et al. Undergraduate students' interaction with online information resources in their academic tasks. Aslib Proceedings, v. 64, n.6, p. 615 - 640, 2012.

HEINSTROM, J; SORMUNEN, E; KAUNISTO-LAINE, S. Spanning information behaviour across the stages of a learning task. Journal of Documentation, v. 70, n. 6, p. 1076 - 1097, 2014.

HWANG, Y. Measuring information behaviour performance inside a company: a case study. Information Research, v. 16, n. 2, p. 1-16, 2011.

LAUDON, K.; LAUDON, J. P. Sistemas de informação gerenciais. 9. ed. São Paulo: Pearson Prentice Hall, 2010.

LE COADIC, Y. F. A ciência da informação. Tradução de Maria Yêda F. S. de Filgueiras Gomes. Brasília: Briquet de Lemos Livros, 1996, 115 p.

MARCHIORI, P. Z. A ciência e a gestão da informação: compatibilidades no espaço profissional. Ciência da Informaçáo, v. 31, n. 2, p. 72-79, 2002.

MARTINEZ-SILVEIRA, M.; ODDONE, N. Necessidades e Comportamento Informacional: Conceituação e Modelos. Ciência da Informação, v. 36, n.1, p. 118-127, 2007.

MENOU, M. J. Information behaviour of the Google generation as a factor in sustainability for Mexican cities. Aslib Proceedings, v. 62, n. 2, p. 165 - 174, 2010.

MILLS, L. A.; KNEZEK, G.; KHADDAGE. F. Information Seeking, Information Sharing, and going mobile: Three bridges to informal learning. Computers in Human Behavior, v. 32, p. 324-334, 2014.

MIZRACHI, D. Undergraduates' Academic Reading Format Preferences and Behaviors. The Journal of Academic Librarianship, v. 41, n. 3, p. 301-311, 2015.

NWAGWU, W. Information sources and information needs of postgraduate students in engineering and arts in the University of Ibadan, Nigeria. Collection Building, v. 31, n. 2, p. $66-77,2012$.

RAMPAZZO, L. Metodologia Científica: para alunos dos cursos de graduação e pósgraduação. 3. ed. São Paulo: Edições Loyola, 2005. 
SAMPIERI, R. H.; COLlADO, C. F.; LUCIO, M. P. B. Metodologia de Pesquisa. 5 ed. Porto Alegre: Editora Penso, 2013.

SILVA, E. L. da; CUNHA, M. V. da. A formação profissional no século XXI: desafios e dilemas. Ciência da Informaçáo, v. 31, n. 3, p. 77-82, 2002.

STEINEROVA, J.; SUSOL, J. Library users in human information behavior. Online Information Review, v. 29, n.2, p. 139-156, 2005.

STOKES, P.; URQUHART, C. Profiling information behavior of nursing students: part 2: derivation of profiles. Journal of Documentation, v. 71, n. 1, p. 52-79, 2015.

TURY, S.; ROBINSON, L.; BAWDEN, D. The Information Seeking Behaviour of Distance Learners: A Case Study of the University of London International Programmes. The Journal of Academic Librarianship, v. 41, n. 3, p. 312-321, 2015.

XAVIER G. M. S. et al. Competência Informacional: Estudo com alunos do curso de Administração. PRETEXTO, v. 14, n. 4, p. 46-64, 2013.

WHITMIRE, E. Discipline differences and undergraduates' information seeking behavior. Journal of the American Society for Information Science and Technology, v. 53, n. 8, p. 631-638, 2002.

WILSON, T. D. Human information behavior. Informing Science, v. 3, n. 2, p. 49-53, 2000. 